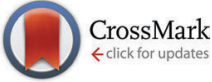

Cite this: New J. Chem., 2016, 40,5495

Received (in Montpellier, France) 16th December 2015, Accepted 25th April 2016

DOI: $10.1039 / c 5 n j 03575 a$

www.rsc.org/njc

\title{
Growth of strontium hydrogen phosphate/gelatin composites: a biomimetic approach
}

\author{
Mazeyar Parvinzadeh Gashti, ${ }^{\star a}$ Manuela Stir ${ }^{\mathrm{b}}$ and Jürg Hulliger ${ }^{\mathrm{b}}$
}

\begin{abstract}
Recent research has focused on the crystal growth of strontium phosphates via different methods due to the bioactivity and biocompatibility of these materials with bone tissue. Here, we use a biomimetic method to synthesize strontium hydrogen phosphate/gelatin composites via single diffusion in gelatin. We compare the composite crystals with analytical-grade strontium hydrogen phosphate using infrared spectroscopy (IR), scanning electron microscopy (SEM), thermal gravimetric analysis, and X-ray diffraction. The IR spectra reveal that gelatin is incorporated into strontium hydrogen phosphate crystals due to $\mathrm{CH}_{2}$ and amide I vibrations. The SEM data exhibit arrow-like crystals and microspheres of strontium hydrogen phosphate with bundled nano-flakes and flower-like surface arrangements of crystals. Furthermore, we find that the thermal stability of the strontium hydrogen phosphate/gelatin composite crystals is higher than that of the analytical-grade strontium hydrogen phosphate. The ion concentration and the preparation method had only a small influence on the broadening of the $X$-ray Bragg reflections. Our study confirms that gelatin is a useful hydrogel for studying the crystallization of strontium hydrogen phosphate.
\end{abstract}

\section{Introduction}

Strontium has been demonstrated as a trace element in the human body that effectively stimulates bone formation and remodeling. ${ }^{1-4} \mathrm{SrHPO}_{4}$ (SrHP) as one of its main compounds has been considered to be an ion exchanger biomaterial for holding both hydrogen phosphate $\left(\mathrm{HPO}_{4}{ }^{2-}\right)$ and strontium $\left(\mathrm{Sr}^{2+}\right)$ ions. ${ }^{5-9}$ A significant deal of attention has been paid to strontium containing hydroxyapatite cements to increase their bioactivity, biocompatibility and compressive strength. ${ }^{10-14}$ The majority of previous studies devoted to the synthesis of SrHP have been focused on the hydrothermal method, ${ }^{15,16}$ cathodic reduction ${ }^{17}$ and solution growing. ${ }^{18-25}$ Taher et al. studied the hydrothermal synthesis of SrHP from a mixture of $\mathrm{Li}_{2} \mathrm{CO}_{3}, \mathrm{SrCO}_{3}$ and $\mathrm{H}_{3} \mathrm{PO}_{4}$ in water after conducting a thermal procedure at $180{ }^{\circ} \mathrm{C}$ for $6 \mathrm{~h}^{15}$ More recently, Zhang et al. developed SrHP nano-belts without any surfactant as the template at $160{ }^{\circ} \mathrm{C}^{16}$ It has been shown that the SrHP coating can be controlled on the cathode via the electrochemical reduction of alkaline earth metal-containing electrolytes. ${ }^{17}$ First introduced by Mooney et al., ${ }^{18,19,21}$ growing solutions of SrHP has been the

\footnotetext{
${ }^{a}$ Young Researchers and Elites Club, Yadegar-e-Imam Khomeini (RAH) Branch, Islamic Azad University, P.O. Box 18155/144, Tehran, Iran.

E-mail: mparvinzadeh@gmail.com; Fax: +98(021)22593135; Tel: +98(0)9123137115

${ }^{b}$ Department of Chemistry \& Biochemistry, University of Berne, Freiestrasse 3, CH-3012 Berne, Switzerland.E-mail: juerg.hulliger@dcb.unibe.ch
}

most popular approach in recent decades. This process consists of the slow evaporation of a solution containing $\operatorname{Sr}\left(\mathrm{NO}_{3}\right)_{2}$ and $\mathrm{NH}_{4} \mathrm{H}_{2} \mathrm{PO}_{4}$, which leads to the precipitation of SrHP. ${ }^{24}$ Furthermore, Roming and Feldman prepared nanoscale SrHP by rapidly mixing $\mathrm{Sr}\left(\mathrm{NO}_{3}\right)_{2}$, diethylene glycol and $\mathrm{H}_{3} \mathrm{PO}_{4}$ in water. These authors found that the rapid cooling of the process temperature from 170 to $15{ }^{\circ} \mathrm{C}$ resulted in the formation of $\alpha$-SrHP and a continuous slow-heating process resulted in the appearance of $\beta$-SrHP. ${ }^{25}$ The only study about SrHP crystallization in gelatin was conducted by Banks et al. who focused on double diffusion in a gel. These authors, who found that polycrystalline spherulites of SrHP were formed in gelatin, did not discuss the morphology of the crystals or the influence of the gel on the crystallization. ${ }^{26}$ The question, therefore, arises of how the polar domains of gelatin influence the SrHP nucleation and morphology. In 2013, we aimed to study the effect of glutamic acid on the biomineralization of brushite in gelatin hydrogel. Interestingly, we found that glutamic acid capable of changing the morphology of brushite from spherulitic growth to mushroom-like crystals. Such structures were shown to be very similar to brushite kidney stones which play an important role in the study of crystal deposition diseases. Our further studies demonstrated that gelatin, starch and iota-carrageenan gels can modulate the diffusion of barium and calcium ions. ${ }^{27-30}$ In this regard, we reported the novel morphologies of barium hydrogen phosphate in gelatin for different metal phosphate crystals. As a result, the gel $\mathrm{pH}$, the gel type, the concentration of ions as well as the method of crystallization strongly contributed to morphological changes of 
different inorganic-organic composite crystals. Our results strongly revealed that the morphology of crystals is altered and controlled using the gel growth method.

The mineralization of inorganic biocompounds in living organisms typically occurs in collagenous scaffolds. ${ }^{31}$ Here, we use gelatin as a model system for the gel growth of SrHP because it is an irreversibly hydrolyzed form of collagen, the primary organic compound found in bone. Gelatin contains peptides and proteins that are excellent biocompatible and biodegradable materials for bone tissue engineering applications. Furthermore, the gel diffusion method has been shown to be a straightforward, inexpensive and controllable model for the reproduction of biomineralization conditions that occur in nature. ${ }^{32,33}$ This method has been previously employed by several groups to gain new insights into the formation mechanisms of fluorapatite, ${ }^{34}$ brushite, ${ }^{27}$ octacalcium phosphate, ${ }^{30}$ calcium carbonate and calcite. ${ }^{35}$ Hydrogels provide an effective medium with high cross-linking density for controlling the morphology of a crystal by adjusting the ratio of ion diffusion. ${ }^{36}$ On the other hand, SrHP is known as a transient in vivo phase to produce apatite. Strontium ions bear a chemical resemblance to calcium ions due to their charge-to-size ratio, and strontium ions play a special role in bone remodeling via apatite lattice distortion, osteoblast proliferation, osteoclast differentiation, bone strength promotion and alkaline phosphatase activation. ${ }^{10,11}$ These benefits arise because strontium has a larger ionic radius than calcium, which strongly suppresses the biological performance of strontiumcontaining cements. ${ }^{12,13}$

Here, we developed new types of SrHP crystals as key compounds in bone tissue engineering based on our previously stated approaches to calcium hydrogen phosphate and barium hydrogen phosphate. This supports the further understanding of how different parameters in biomineralization via the gel diffusion method affect the morphology of biomimetic composite materials. Therefore, this study may be useful for explaining the mechanisms of biomineralization of phosphate and strontium ions in vivo.

\section{Experimental section}

\subsection{Synthesis of composites}

We dissolved $1 \mathrm{~g}$ of pig skin gelatin (300 bloom, Sigma-Aldrich, USA) in $10 \mathrm{~mL}$ deionized water, and $7.5 \mathrm{cc}$ of $0.5 \mathrm{M} \mathrm{SrCl}_{2}$ solution (Sigma-Aldrich) was added to the dissolved gelatin. The solution was then stirred for $2 \mathrm{~h}$ at $50{ }^{\circ} \mathrm{C}$. The $\mathrm{pH}$ of the mixture was changed using tris(hydroxymethyl)aminoethane/ $\mathrm{HCl}$ (Sigma-Aldrich) to adjust it to a value of 7.4. The mixture was then poured into the tube and left at room temperature for $24 \mathrm{~h}$ until gelation occurred. Next, we added $7.5 \mathrm{cc}$ of $0.5 \mathrm{M}$ $\mathrm{Na}_{2} \mathrm{HPO}_{4}$ solution (Sigma-Aldrich) buffered at $\mathrm{pH} 7.4$ to the top of the gelatin tube. The diffusion was allowed to take place at $25{ }^{\circ} \mathrm{C}$ for 1 month. At the same time, gelatin was mixed with a $\mathrm{Na}_{2} \mathrm{HPO}_{4}$ solution to allow the gelation to come into contact with a buffered $\mathrm{SrCl}_{2}$ solution. In the third single tube, a mixture of gelatin and $0.8 \mathrm{M} \mathrm{Na} \mathrm{HPO}_{4}$ was placed in contact with buffered $1 \mathrm{M} \mathrm{SrCl}_{2}$. SrHP/gelatin composite crystals were produced inside the gel near the interface between the gel and the top liquid in all of the tubes. The samples were washed several times with hot water to remove the excess gel, and the experiments were repeated 10 times for each set of samples.

\subsection{Characterization}

We carried out the chemical characterization of the gelatin and SrHP crystals using a Perkin Elmer Spectrum One IR spectrometer integrated with an IBM personal computer.

We analyzed the surface morphology of the composite crystals by means of a Hitachi scanning electron microscope S-3000 N. The samples were covered with a layer of gold under vacuum conditions prior to the measurement.

We performed thermogravimetric analysis on a Mettler-Toledo TG/SDTA 851e analyser. In each case, a $5 \mathrm{mg}$ sample was examined under an $\mathrm{N}_{2}$ atmosphere at a heating rate of $5{ }^{\circ} \mathrm{C} \mathrm{min}-1$ from 30 to $600{ }^{\circ} \mathrm{C}$.

We collected powder X-ray diffraction patterns at ambient temperature using a STOE StadiP diffractometer in the reflection Bragg-Brentano geometry (monochromatic $\mathrm{Cu} \mathrm{K} \alpha_{1}$ radiation, wavelength $\lambda=0.15406 \mathrm{~nm}$ ). The scattered intensity was detected using a linear position sensitive detector.

\section{Results and discussion}

\subsection{Chemical characterization}

The infrared (IR) spectra of pure gelatin, SrHP (Sigma-Aldrich) and SrHP/gelatin composite crystals are shown in Fig. 1. In gelatin, evidence for amide I and amide A consists of two strong peaks at 1644 and $3423 \mathrm{~cm}^{-1}$ for a random coil and the $\alpha$-helix conformation of gelatin, respectively. ${ }^{37,38}$ These bands are obvious based on $\mathrm{C}=\mathrm{O}$ stretching coupled with $\mathrm{COO}^{-}$vibrations and NH stretching coupled with hydrogen bonding. The signature of amide II in gelatin is seen in a band at $1534 \mathrm{~cm}^{-1}$ for an out-ofphase combination of $\mathrm{CN}$ stretching and in-plane $\mathrm{NH}$ deformation modes of the peptide groups. ${ }^{39}$ On the other hand, the $\mathrm{NH}$ bending of amide III is evidenced by the peak at $1233 \mathrm{~cm}^{-1}$. Moreover, all of the bands at 1384, 1400, 1437 and $2933 \mathrm{~cm}^{-1}$ appeared for $\mathrm{CH}_{2}$ wagging and the asymmetrical $\mathrm{CH}_{2}$ stretching of proline. We assign the bands at 1163,1079 and $1030 \mathrm{~cm}^{-1}$ to the carbonyl and the skeletal vibrations of gelatin. ${ }^{40,41}$

Analytical-grade SrHP provided by Sigma-Aldrich (Fig. 1b) was used as a reference for comparison with different SrHP/ gelatin composite crystals obtained in this study (Fig. 1, panels c-e). Four intense bands at 3428, 2813, 2390 and $1719 \mathrm{~cm}^{-1}$ are related to $\mathrm{H}_{2} \mathrm{O}$ bending, hydrogen bonding, $\mathrm{O}-\mathrm{H}$ stretching of the hydrogen phosphate anions and vibration of the hydrogen ions in the $\mathrm{H}^{+}-\mathrm{PO}_{4}{ }^{3-}$ contacts, respectively. ${ }^{28,30,42,43}$ The bands located in the range $1400-1200 \mathrm{~cm}^{-1}$ are attributed to the in-plane $\mathrm{P}-\mathrm{O}-\mathrm{H}$ bending modes. The $\mathrm{PO}$ asymmetric and symmetric stretching modes in the $\mathrm{PO}_{4}{ }^{3-}$ fragment of SrHP are associated with the three strong bands at 1131, 1077 and $991 \mathrm{~cm}^{-1}$. The symmetric stretching of $\mathrm{P}-\mathrm{O}(\mathrm{H})$ is represented by a strong band at $877 \mathrm{~cm}^{-1}$. The bands in the range $600-400 \mathrm{~cm}^{-1}$ 


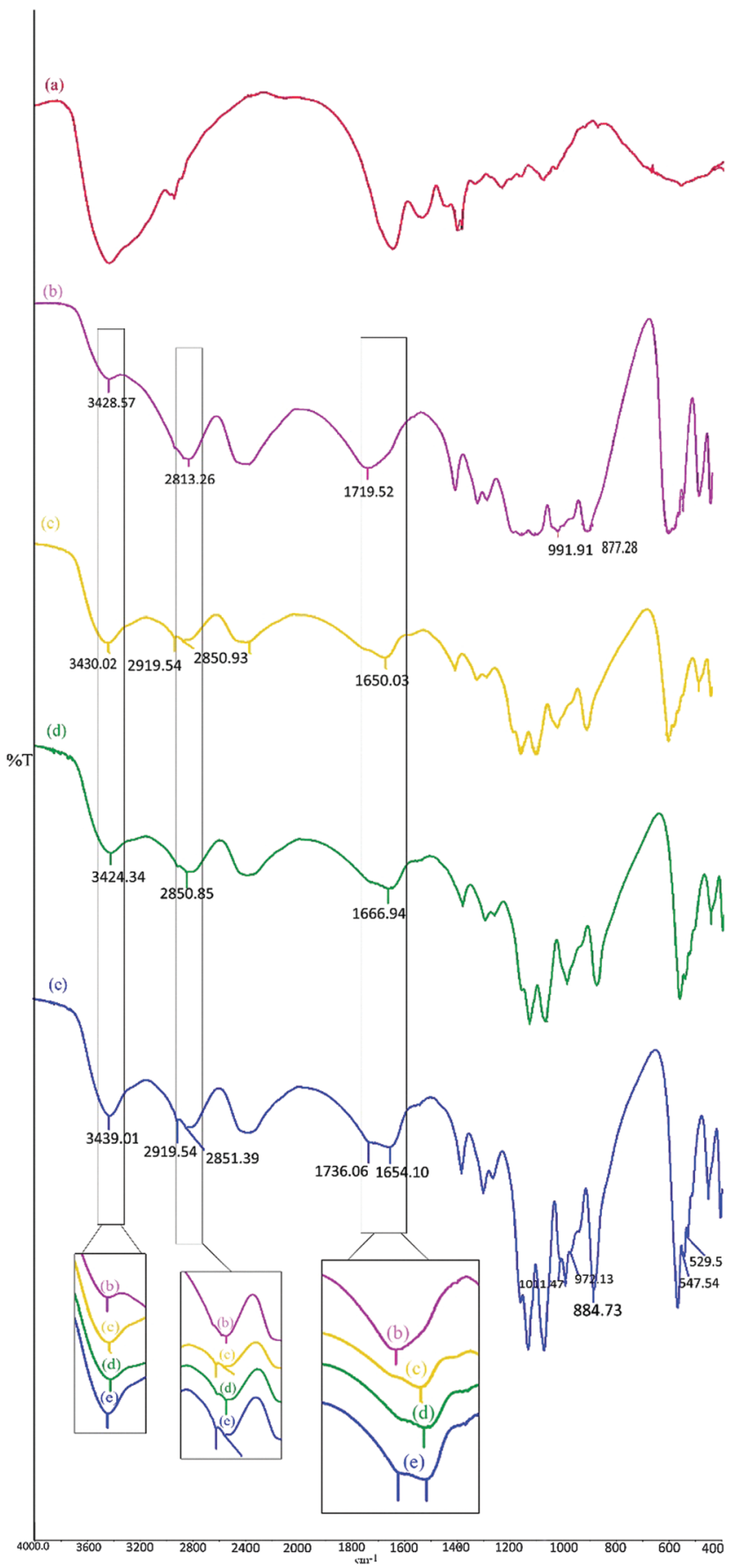

Fig. 1 The IR spectra of (a) gelatin, (b) analytical grade SrHP (SigmaAldrich), (c) SrHP crystals prepared in tube 1, (d) SrHP crystals prepared in tube 2, and (e) SrHP crystals prepared in tube 3.

arise from the $\mathrm{P}-\mathrm{O}$ anti-symmetric and symmetric bending modes in the $\mathrm{PO}_{4}{ }^{3-}$ - fragment. ${ }^{25}$

The IR spectrum for the crystals collected from tube 1 (Fig. 1c) revealed the appearance of two new peaks at 2919 and $2850 \mathrm{~cm}^{-1}$ after the crystallization of SrHP in gelatin and the intensity of the band at $3430 \mathrm{~cm}^{-1}$ increased. Furthermore, the peak at $1719 \mathrm{~cm}^{-1}$ (in Fig. 1b) was shifted to $1650 \mathrm{~cm}^{-1}$ (in Fig. 1c) and the band at $511 \mathrm{~cm}^{-1}$ disappeared compared with analytical grade SrHP. For the crystals produced in tube 2 (Fig. 1d), we observed several changes including the appearance of a new peak at $2850 \mathrm{~cm}^{-1}$, shifting of a band from 1719 to $1666 \mathrm{~cm}^{-1}$ and disappearance of a peak at $511 \mathrm{~cm}^{-1}$. On the other hand, the collected crystals from tube 3 (Fig. 1e) showed an increase in the intensity of the band at $3439 \mathrm{~cm}^{-1}$; the appearance of several new peaks at 2919, 2851, 1654, 1011, 972, 547, 542 and $529 \mathrm{~cm}^{-1}$; and the disappearance of a peak at $511 \mathrm{~cm}^{-1}$ as well as shifting of bands at 1719 and $877 \mathrm{~cm}^{-1}$ to 1736 and $844 \mathrm{~cm}^{-1}$, respectively.

As previously stated, polypeptide chains generally produce several characteristic bands as amide A (about $3500 \mathrm{~cm}^{-1}$ ), amide B (about $3100 \mathrm{~cm}^{-1}$ ), amide I $\left(1600-1700 \mathrm{~cm}^{-1}\right.$ ), amide II $\left(1550 \mathrm{~cm}^{-1}\right)$ and amide III $\left(1300-1350 \mathrm{~cm}^{-1}\right)$. In other words, $\mathrm{CH}$ bonds can be vibrated at $2850-3100 \mathrm{~cm}^{-1}$ depending on the vibration mode. According to all the FTIR results, all the changes in the FTIR spectra of crystals associated with the above-mentioned regions are due to the fact that gelatin is entrapped within the crystal sheets. In this regard, we previously measured the gelatin content in barium hydrogen phosphate and calcium hydrogen phosphate crystals to be about 2-3 wt\%. We also stated that the changes occurred in the FTIR spectra of composite crystals produced in biopolymeric gels depend on the ion concentration, gel $\mathrm{pH}$ and ion diffusion method. This observation is confirmed in the FTIR spectra of SrHP/gelatin composites where the type of ion firstly diffused and the ion concentration was different.

Note that we have previously demonstrated similar peak changes in amide I after the incorporation of gelatin into calcium hydrogen phosphate and barium hydrogen phosphate minerals. Such intermolecular interactions were due to hydrogen bonds and the coupling of positive ions with the gelatin carboxylate anions. ${ }^{27,28}$ The ionic strength of proteinous gels can be further enhanced via salts, which may lead to more rigid conformations of peptides and changes in the ordering of triple helices, as was found by Feng et al. ${ }^{44}$ Furthermore, the intensity of the amide $\mathrm{A}$ bands and the $\mathrm{CH}_{2}$ stretching of gelatin were not the same for the SrHP samples in different tubes. This result clearly demonstrates that the interaction between gelatin and ions is dependent on the type of ion diffusing in the gel and the ion concentration.

\subsection{Microscopic observation of composite crystals}

Fig. 2 illustrates the morphology of SrHP/gelatin composites obtained from the gel diffusion. We observed two different morphologies for the SrHP/gelatin composites: arrow-like and spherulitic crystals. In the first tube, arrow-like crystals approximately $60 \mu \mathrm{m}$ in width and $300 \mu \mathrm{m}$ in length were obtained. These crystals were composed of aligned bundles of single crystals, which functioned as the building blocks of a three-dimensional supercomposite crystal. We also observed highly porous microspheres in all of the tubes. The surface of the spheres in tube 1 (Fig. 2c and d) included bundled nano-flakes originating from a common center with a thickness of approximately $140 \mathrm{~nm}$. It was obvious from tubes 2 and 3 that the crystalline structure of SrHP was similar to that of the spheres in tube 1. However, their surface morphology was 


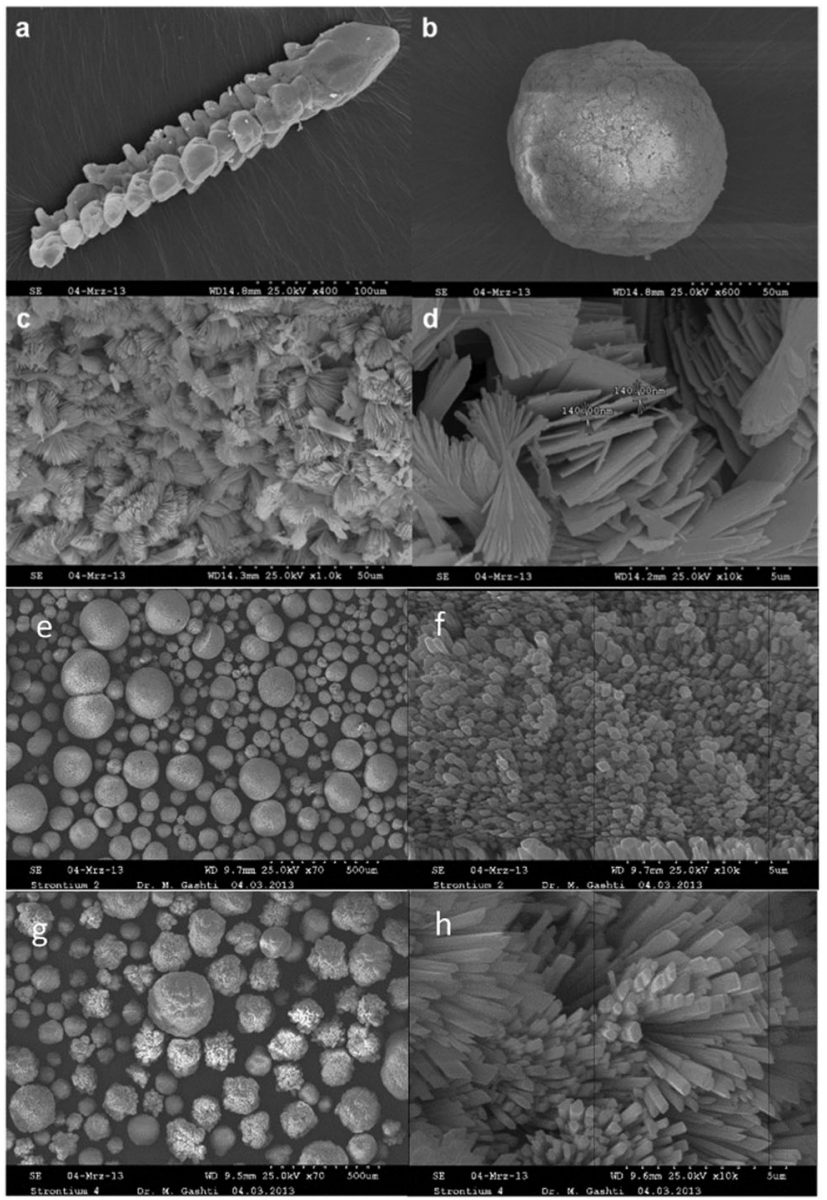

Fig. 2 SEM images of SrHP/gelatin composites: (a) arrow-like composites obtained in tube 1, (b) spherulitic composites obtained in tube 1, (c and d) the surface of spherulitic crystals obtained in tube 1 with higher magnification, (e) spherulitic composites obtained in tube 2 at low magnification, (f) spherulitic composites obtained in tube 2 at high magnification, (g) spherulitic composites obtained in tube 3 at low magnification, and (h) spherulitic composites obtained in tube 3 at high magnification.

different depending on the variation of the molarity of the ions and the type of ion diffused in the gelatin. It should be noted that the molarities of $\mathrm{HPO}_{4}{ }^{2-}$ and $\mathrm{Sr}^{2+}$ were similar for tubes 1 and 2 but different for the diffusion procedure in the gel. This situation resulted in changes in the crystallization and was responsible for the absence of arrow-like crystals in tube 2 . Moreover, the molarity of ions in tube 3 was higher than that in tube 2, which possibly changed the surface arrangement, roughness and porosity of the spheres. The spheres in tube 2 were more uniform compared with those in tube 3, and twodimensional bundled sheets were arranged on the surface of spheres via self-assembly. As a result, spheres with flower-like surface arrangements were generated (Fig. 2, panels e-h).

We previously demonstrated that the crystal growth habits of barium hydrogen phosphate and calcium hydrogen phosphate crystals in gels depended on several factors including the electrostatic charge density, the topology of the binding surface, van der Waals forces, the surface distribution of biopolymers and the type and sequence of the functional groups. ${ }^{27,28,45,46}$ Researchers have found that gelatin macromolecular chains have randomly coiled and untangled single conformations in water at about $40-50{ }^{\circ} \mathrm{C}$ (i.e., their melting point region). These chains have a reduced energy level at lower temperatures. In this regard, three individual helices are organized into a clockwise triple-helix rich in glycineproline-hydroxyproline amino acids. Hydrogen bonds among the peptide groups play a pivotal role in the stabilization of this structure. It has been shown that the nucleation and growth of crystals in gelatin are influenced by the impregnation of calcium, barium and phosphate ions. In this regard, pre-ordering of the gelatin network is related to the type of the first ion impregnated in the gel prior to the diffusion of a second ion. Since the $\mathrm{HPO}_{4}{ }^{2-}$ ion was mixed with gelatin in tubes 2 and 3 , it interacted with the outer surface of the protein helices, which resulted in the bending of the triple-helices and the formation of hydrogen and electrostatic bondings. ${ }^{47}$ The $\mathrm{Sr}^{2+}$ cations, which are diffused later, were able to react with the aggregated $\mathrm{HPO}_{4}{ }^{2-}$ ions in gelatin to induce the crystallization of SrHP. This mechanism differs from the as-prepared mixture of gelatin and $\mathrm{Sr}^{2+}$, which possibly resulted in changes in the crystallization mechanism and morphology of the SrHP/gelatin composites. We conclude that the experimental conditions included the ion concentrations and the type of ion impregnated in the gel control, the reactant diffusion and the morphology of the SrHP crystals.

\subsection{Thermal studies}

Fig. 3 shows the thermal degradation of SrHP/gelatin composites and analytical-grade SrHP crystals. We observed three zones or regions of decomposition - initial, main and char - for all of the samples. In the first zone, the weight loss is the result of the removal of surface-adsorbed water molecules. ${ }^{48} \mathrm{The}$ SrHP/gelatin composites lost about $3 \%$ of their weight in the first region, which was negligible for the analytical-grade SrHP crystals. ${ }^{25}$ Significant weight loss for the analytical-grade SrHP crystals occurred at earlier temperatures of the second region between 310 and $350{ }^{\circ} \mathrm{C}$ due to the generation of $\mathrm{Sr}-\mathrm{O}-\mathrm{P}_{2} \mathrm{O}_{5}$, as stated by Sales et al. However, a higher thermal stability of the SrHP/ gelatin composites was observed by shifting the second zone to temperatures between 410 and $470{ }^{\circ} \mathrm{C} .{ }^{23}$ This finding may be due to strong interactions between the inorganic and organic compounds. We observed that the degradation of composites started at $470{ }^{\circ} \mathrm{C}$, which was most definitely higher than the

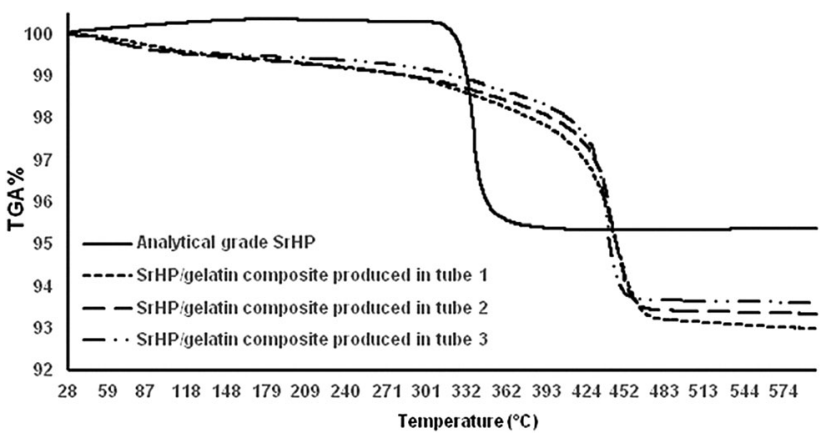

Fig. 3 TGA curves for analytical grade SrHP and SrHP/gelatin composites. 
degradation level of $450{ }^{\circ} \mathrm{C}$ observed for analytical-grade SrHP pure crystals. We have previously shown the pyrolytic split between the polar domain of amine and carboxylic acids in gelatin on the one hand and the strontium and phosphate ions of SrHP on the other hand in composites of barium hydrogen phosphate/gelatin and calcium hydrogen phosphate/gelatin. ${ }^{28}$ Furthermore, we observed that the char content was dissimilar for the SrHP/gelatin composites produced in different tubes at temperatures higher than $470{ }^{\circ} \mathrm{C}$. This result further confirms the interaction between gelatin and SrHP, which is in agreement with the findings of the IR spectra.

\subsection{X-ray diffraction analysis}

The X-ray powder diffraction patterns revealed a single crystalline phase, $\alpha-\mathrm{SrHPO}_{4}$ (PDF 01-070-1215), for all the samples (S1, S2 and S3) synthesized in the presence of gelatin (Fig. 4).

We used pattern decomposition to investigate the influence of the amount of gelatin and the preparation method on the crystals' structure and the line broadening of the SrHP Bragg reflections. The monotonic increase in the intensity of the (120) reflection as a function of the amount of gelatin (Fig. 4) may well suggest a gelatin-induced preferential (textured) growth of the SrHP crystals with respect to the (120) planes.

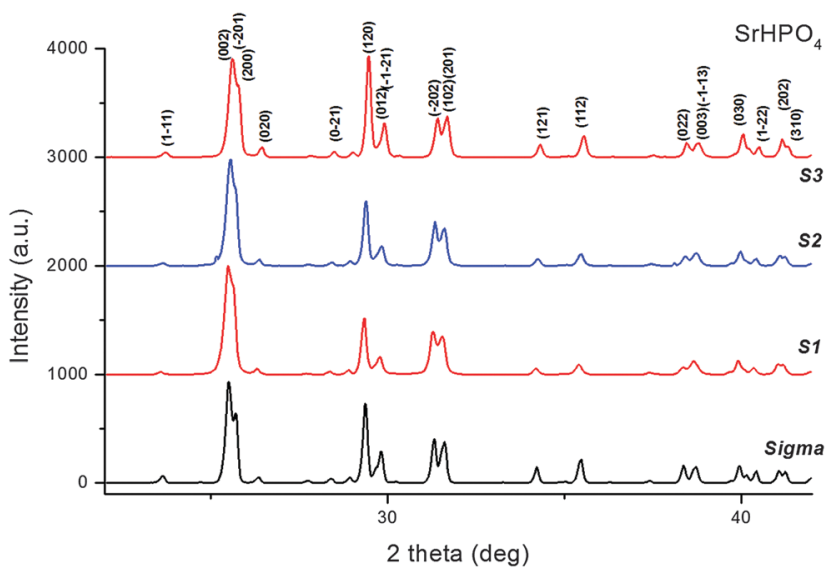

Fig. 4 X-ray diffraction patterns collected on specimen tubes 1-3 and on the reference sample (Sigma-Aldrich).

Table 1 Crystallite size for samples in tube 1-3 and a Sigma-Aldrich reference sample

\begin{tabular}{lllll}
\hline$h k l$ & $G \mathrm{~S} 1(\mathrm{~nm})$ & $G \mathrm{~S} 2(\mathrm{~nm})$ & $G \mathrm{~S} 3(\mathrm{~nm})$ & $G$ Sigma $(\mathrm{nm})$ \\
\hline$(002)$ & 45.90 & 45.75 & 46.02 & 50.11 \\
$(120)$ & 59.74 & 66.66 & 66.72 & 67.34
\end{tabular}

In terms of the hypothesis of negligible micro-strain, we applied the Scherrer eqn (1) to quantitatively estimate the size of the coherent scattering domains (i.e., the crystallite size):

$$
G_{h k l}=\frac{K \lambda}{\beta \cos \theta_{h k l}}
$$

where $K$ is the shape constant (here $K=1$ ), $\lambda$ is the X-ray wavelength (here $\lambda=0.15406 \mathrm{~nm}, \mathrm{Cu} \mathrm{K}$ radiation), $\beta$ is the fullwidth at half maximum (FWHM, in radians) and $\theta_{h k l}$ is the Bragg angle of the diffraction line with Miller indices $(h k l)$.

In Table 1 , we relate $G_{002}$ to the mean crystallite size normal to the $(002)$ plane; $G_{120}$ refers to the mean crystal size along a direction perpendicular to the $(120)$ planes.

The difference in the crystallite size values in different directions suggests that the crystallites possess a needle or plate-like shape, which is in agreement with the scanning electron microscopy (SEM) results (see, for example, Fig. $2 \mathrm{~d}, \mathrm{f}$ and $h$ ). The values of the lattice parameters did not change significantly as a function of the preparation method or the ion concentration (Table 2).

We refined the lattice parameters using the powder diffraction file of triclinic $\alpha-\mathrm{SrHPO}_{4}$ (PDF 01-070-1215, space group P1 (point group 1 , centrosymmetric)).

\section{Summary and conclusion}

In this work, we have investigated the influence of gelatin and the concentration of ions and their diffusion on the preparation of SrHP/gelatin biocomposite crystals using various analytical techniques. IR spectra revealed strong interactions among the gelatin functional groups and the strontium and phosphate ions, which promoted the formation of composites. The IR results also confirmed that the carboxylate, amine and hydroxyl groups of gelatin provided the crystal backbone precursors for the nucleation and growth of SrHP. As a result, various morphologies were produced such as micro-crystals, spheres and nano-flakes. The macromolecular conformation of double helices in gelatin in the presence of strontium cations or phosphate anions induced pre-structural disorder for SrHP deposition via the production of highly porous spheres. Our findings clearly show that gelatin can produce novel SrHP crystal morphologies depending on the first ion diffused and the ion concentrations. Such morphologies have not yet been reported elsewhere. Irrespective of the ion concentrations, the single-diffusion method leads to the formation of single-phase $\alpha$-SrHPO 4 . Our SrHP-gelatin composites contribute to a better understanding of the mechanisms of mineralization of strontium and phosphate ions in bone tissue. However, additional studies

Table 2 Lattice parameters for samples in tube 1-3 and a Sigma-Aldrich reference sample

\begin{tabular}{|c|c|c|c|c|c|c|}
\hline Samples & $a(\AA)$ & $b(\AA)$ & $c(\AA)$ & $\alpha(\mathrm{deg})$ & $\beta$ (deg) & $\gamma(\mathrm{deg})$ \\
\hline S1 (tube 1) & $7.1870(12)$ & $6.7921(9)$ & $7.2606(10)$ & $94.651(14)$ & $104.954(16)$ & $88.778(16)$ \\
\hline S2 (tube 2) & $7.1721(25)$ & $6.7829(16)$ & $7.2462(19)$ & $94.660(26)$ & $104.967(28)$ & $88.733(33)$ \\
\hline S3 (tube 3) & $7.1476(35)$ & $6.7582(27)$ & $7.2403(23)$ & $94.520(42)$ & $105.021(36)$ & $88.691(50)$ \\
\hline Sigma & $7.1774(20)$ & $6.7878(15)$ & $7.2532(17)$ & $94.613(24)$ & $105.070(28)$ & $88.759(27)$ \\
\hline
\end{tabular}


should focus on different factors such as the gel type and $\mathrm{pH}$, the type of diffusion method, the duration of the diffusion process and the gel concentration.

\section{Acknowledgements}

This project was supported by SNF project no. 200020_146413. We thank Mrs Beatrice Frey for providing SEM images and Dr Matthias Burgener for assistance and support.

\section{References}

1 G. Romieu, X. Garric, S. Munier, M. Vert and P. Boudeville, Acta Biomater., 2010, 6, 3208-3215.

2 H. B. Pan, Z. Y. Li, W. M. Lam, J. C. Wong, B. W. Darvell, K. D. K. Luk and W. W. Lu, Acta Biomater., 2009, 5, 1678-1685.

3 P. E. Kazin, A. S. Karpov, M. Jansen, J. Nuss and Y. D. Tretyakov, Z. Anorg. Allg. Chem., 2003, 629, 344-352.

4 G. M. Kuang, W. P. Yau, W. M. Lam, J. Wu, K. Y. Chiu, W. W. Lu and H. Pan, J. Biomed. Mater. Res., Part B, 2012, 100, 778-787.

5 F. Q. Zhuang, R. Q. Tan, W. F. Shen, X. P. Zhang, W. Xu and W. J. Song, Acta Metall. Sin., 2015, 28, 438-443.

6 D. Guo, K. Xu, X. Zhao and Y. Han, Biomaterials, 2005, 26, 4073-4083.

7 W. Zhang, Y. Shen, H. Pan, K. Lin, X. Liu, B. W. Darvell, W. W. Lu, J. Chang, L. Deng, D. Wang and W. Huang, Acta Biomater., 2011, 7, 800-808.

8 W. M. Lam, H. B. Pan, Z. Y. Li, C. Yang, W. K. Chan, C. T. Wong, K. D. K. Luk and W. W. Lu, Ceram. Int., 2010, 36, 683-688.

9 E. A. Abdel-Aal, Int. J. Nanopart., 2011, 4, 77-92.

10 M. Schumacher, A. Henß, M. Rohnke and M. Gelinsky, Acta Biomater., 2013, 9, 7536-7544.

11 T. G. Kim and B. Park, Inorg. Chem., 2005, 26, 9895-9901.

12 G. Bechkoff, J. Radisson, L. Bessueille, K. BouchekiouaBouzaghou and R. Buchet, Biochem. Biophys. Res. Commun., 2008, 29, 378-381.

13 D. Guo, M. Mao, W. Qi, H. Li, P. Ni, G. Gao and K. Xu, J. Mater. Sci.: Mater. Med., 2011, 22, 2631-2640.

14 H.-B. Pan, Z.-Y. Li, T. Wang, W. M. Lam, C. T. Wong, B. W. Darvell, K. D. K. Luk, Y. Hu and W. W. Lu, Cryst. Growth Des., 2009, 9, 3342-3345.

15 L. B. Taher, L. Smiri, Y. Laligant and V. Maisonneuve, J. Solid State Chem., 2000, 152, 428-434.

16 Y. Zheng, Y. Cheng, Y. Wang, Y. Yu, D. Chen and F. Bao, J. Cryst. Growth, 2005, 280, 569-574.

17 M. Dinamani and P. Vishnu Kamath, Mater. Res. Bull., 2001, 36, 2043-2050.

18 R. W. Mooney, M. A. Aia, C. W. W. Hoffman and R. C. Ropp, J. Am. Chem. Soc., 1959, 81, 826-829.

19 R. C. Ropp, M. A. Aia, C. W. W. Hoffman, T. J. Veleker and R. W. Mooney, Anal. Chem., 1959, 31, 1163-1166.

20 M. H. Frere, Soil Sci. Soc. Am. J., 1962, 26, 48-51.
21 M. A. Aia, J. E. Mathers and R. W. Mooney, J. Chem. Eng. Data, 1964, 9, 335-338.

22 T. P. Feenstra, H. A. Van Straten and P. L. De Bruyn, J. Colloid Interface Sci., 1981, 80, 255-270.

23 B. C. Sales, B. C. Chakoumakos, L. A. Boatner and J. O. Ramey, J. Non-Cryst. Solids, 1993, 159, 121-139.

24 B. Louati, K. Guidara, M. Gargouri and M. Fourati, Z. Naturforsch., 2005, 60, 121-126.

25 M. Roming and C. Feldmann, J. Mater. Sci., 2008, 43, 5504-5507.

26 E. Banks, R. Chianelli and F. Pintchovsky, J. Cryst. Growth, 1973, 18, 185-190.

27 M. Parvinzadeh Gashti, M. Bourquin, M. Stir and J. Hulliger, J. Mater. Chem. B, 2013, 1, 1501-1508.

28 M. Parvinzadeh Gashti, M. Burgener, M. Stir and J. Hulliger, J. Colloid Interface Sci., 2014, 431, 149-156.

29 M. Parvinzadeh Gashti, M. Bourquin, M. Stir and J. Hulliger, Cryst. Growth Des., 2013, 13, 2166-2173.

30 M. Parvinzadeh Gashti, M. Stir and J. Hulliger, Colloids Surf., B, 2013, 110, 426-433.

31 H. Cölfen and M. Antonietti, Angew. Chem., Int. Ed., 2005, 44, 5576-5591.

32 S. V. Dorozhkin, Biomaterials, 2010, 31, 1465-1485.

33 J. L. Gornall and E. M. Terentjev, Soft Matter, 2008, 4, 544-549. 34 H. Tlatlik, P. Simon, A. Kawska, D. Zahn and R. Kniep, Angew. Chem., Int. Ed., 2006, 45, 1905-1910.

35 F. C. Meldrum and H. Cölfen, Chem. Rev., 2008, 108, 4332-4432.

36 M. Burgener, T. Putzeys, M. Parvinzadeh Gashti, S. Busch, H. Oulevey Aboulfadl, M. Wübbenhorst, R. Kniep and J. Hulliger, Biomacromolecules, 2015, 16, 2814-2819.

37 M. Parvinzadeh Gashti, D. Hegemann, M. Stir and J. Hulliger, Plasma Processes Polym., 2014, 11, 37-43.

38 M. C. Chang, C. C. Ko and W. H. Douglas, Biomaterials, 2003, 24, 2853-2862.

39 K. J. Payne and A. Veis, Biopolymers, 1988, 27, 1749-1760.

40 M. Parvinzadeh Gashti and A. Almasian, Composites, Part B, 2013, 52, 340-349.

41 C. Pouchert, The Aldrich Library FTIR Spectra, Aldrich Chemical Company, Milwaukee, 1985.

42 J. H. Muyonga, C. G. B. Cole and K. G. Duodu, Food Chem., 2004, 86, 325-332.

43 M. Parvinzadeh, S. Moradian, A. Rashidi and M. E. Yazdanshenas, Appl. Surf. Sci., 2010, 256, 2792-2802.

44 Y. Feng, M. Taraban and Y. Bruce Yu, Soft Matter, 2012, 1, 11723-11731.

45 S. Schweizer and A. Taubert, Macromol. Biosci., 2007, 7, 1085-1099.

46 K. Gorna, R. Muñoz-Espí, F. Gröhn and G. Wegner, Macromol. Biosci., 2007, 7, 163-173.

47 D. Zahn, O. Hochrein, A. Kawska, J. Brickmann and R. Kniep, J. Mater. Sci., 2007, 42, 8966-8973.

48 M. Parvinzadeh Gashti, M. Yousefpour Navid and M. H. Rahimi, Pigm. Resin Technol., 2013, 42, 34-44. 